\title{
Growing $\mathrm{Cd}_{0.25} \mathrm{Hg}_{0.75} \mathrm{Se}$ layers by laser evaporation in static vacuum
}

\author{
B.N. Gritsook, I.M. Fodchoock, S.V. Nichiy, U.S. Paranchich, R.L. Politanskiy \\ Chernivtsi Yu. Fed'kovich University, 2 Kotsyubinsky str., 58012, Chernivtsi, Ukraine
}

\begin{abstract}
Cd}_{0.25} \mathrm{Hg}_{0.75} \mathrm{Se}$ films received by laser evaporation method in conditions of static vacuum are investigated. Optimum temperature of a substrate is ascertained using structural and electrophysical measurements. It is shown that the used method enables one to receive films of $\mathrm{Cd}_{\mathrm{x}} \mathrm{Hg}_{1-\mathrm{x}} \mathrm{Se}$ solid solutions close to bulk material by their properties.
\end{abstract}

Keywords: semiconductor film, laser evaporation, electron diffraction, Hall coefficient.

Paper received 22.10.99; revised manuscript received 04.11.00; accepted for publication 12.12.00.

Growing layers with determined structure of semiconductor bonds is a difficult technological problem $[1,2]$. It is connected with usage of conventional growing methods, for example, the thermal evaporation in vacuum. In this method, after melting, stuff appears to be decomposed onto making components evaporated with various rates. The composition of vapor is determined by quantitative ratio of components in a melted stuff and pressure of their vapors. In the course of spraying, a composition of vapor varies, and this leads to a variable structure of growing films, and, as a consequence to their changeable properties. As a rule, at the beginning of deposition, films are enriched by a volatile component, and at the end by nonvolatile. Using different variants of thermal evaporation (from a pair of crucibles, flash-method and so on) not always give reproducible results. Therefore, such method is mainly used for growing films of elementary substances.

Decomposition of substance can be avoided for growing films by a method of cathode spraying from solid phase. However, in this method the process occurs in ambient inert gas, which is continuously pumped through the chamber. As a result, impurities present in gas environment, interact with sprayed substance and pollute it. Therefore, cathodic spraying is used for growing layers of high-temperature metal substances, in which the small quantities of impurities do not influence essentially on their properties [3,4].

In indicated cases, as it also concerns to other known methods of growing, the growth of films occurs at continuous pumping a system out, i.e. in conditions of dynamic vacuum [5]. In the process of pumping out such systems, some amounts of working liquid vapor from pumps appear in a technological volume in the same way as it occurs due to penetration of air. Under action of electromagnetic fields or high temperatures they interact with sprayed substance forming compounds or are introduced in it and cause changing a structure of layers.

Recently for growing layers laser radiation [6] was used. In this method, in the area of irradiation, the evaporation of a substance occurs «instantly», that excludes convectional mixing of a liquid, as well as interaction of melted substance with stuff of evaporator is eliminated, which essentially differs from a method of thermal evaporation. The important factor influencing on purity of growing layers is pressure in an operation chamber. It depends on quantity of gas flowing into a system and on rate of pumping out. Take into account that flowing occurs continuously, therefore constant pollution of a film at stages of vapor transfer from a source to a substrate and their condensation take place.

For growing layers $\mathrm{Cd}_{0.25} \mathrm{Hg}_{0.75} \mathrm{Se}$ we use a technique of laser evaporation in conditions of static vacuum [7]. This technique has certain advantages against other methods: a) permits to grow films in conditions of higher vacuum, than that reached in dynamic vacuum systems; b) does not connect with flowing gases and their active polluting the films; c) is practically free of energy losses when maintaining vacuum.

Growing layers was carried out in sealed glass ampoule, in which titanium plate, evaporated material and substrate were previously loaded. Ampoules were previously pumped out to pressure of $10^{-5}-10^{-6}$ Torr, heated with the purpose of excluding and then unsolded. 


\section{B.N. Gritsook et al.: Growing $\mathrm{Cd}_{0.25} \mathrm{Hg}_{0.75}$ Se layers by laser evaporation ...}

Spraying titanium plate with pulses of the laser «Quant-12» attained further decrease of pressure in ampoule. Deposited on an internal wall friable titanium film reacted with such active components of residual gas as oxygen and nitrogen, as well as penetration of titanium vapors into the space «evaporated material - substrate» was excluded. As a result of absorption of active gases, the pressure in ampoule is lowered up to $10^{-7}-10^{-8}$ Torr.

Growing layers was performed on a substrate made of glass, $\mathrm{NaCl}$ and mica of the STA grade. Temperature of substrate was set by outside oven with resistive heating. As it was shown experimentally, the thermal balance between oven and substrate was reached in 20 minutes. Then the oven was tuned to a given temperature mode. The control of temperature was provided by a thermocouple, which was fixed between heater and ampoule. Layers were grown under power density of irradiation equal to $6.4 \mathrm{~kW}$ per $\mathrm{cm}^{2}$, duration of pulses $1.5 \mathrm{~ms}$ and frequency of pulses $15 \mathrm{~Hz}$. Rate of growth was equal to $0.5 \AA$ / pulse. Layers grown in such conditions have a mirror surface inherent to bulk material. Thicknesses of layers were measured using multibeam interferometer MII-11 and comprised the range of 0.1$0.2 \mu \mathrm{m}$.

The properties of semiconducting layers are determined by impurities as well as structural defects. The latter can arise during layer deposition as a result of component separation. It especially concerns to substances containing such easily volatile components as mercury, for example.

For researching crystal structure of layers $\mathrm{Cd}_{0.25} \mathrm{Hg}_{0.75} \mathrm{Se}$ we used diffraction of fast electrons. In Fig.1 shown are images of layers grown at various temperatures of substrates. From the analysis of such images, obtained at accelerating voltage $60 \mathrm{kV}$, it was established that layers grown at temperatures of a substrate up to $90^{\circ} \mathrm{C}$ have polycrystalline structure with inclusions of an amorphous phase (Fig. 1a). This phase practically escapes at increasing temperature of the substrate up to $110^{\circ} \mathrm{C}$ (Fig. 1b). At substrate temperature equal to $120^{\circ} \mathrm{C}$, layers have not already amorphous phase (Fig. 1c).

The $\mathrm{Cd}_{0.25} \mathrm{Hg}_{0.75} \mathrm{Se}$ crystal is related to cubic syngony with a lattice constant equal to $6.082 \AA$. Performed identification of electronic images in Fig. 1 has allowed to establish that reflecting planes are (111), (200) and (311). It permits to conclude that growing layers on a crystal structure correspond to initial material.

The research of transport phenomena was carried out using layers $\mathrm{Cd}_{0.25} \mathrm{Hg}_{0.75} \mathrm{Se}$ grown at various temperatures $T_{n}$ of a substrate by the method described in [8]. Layers for measurements were deposited through a mask, in which lines for drawing contact areas were present. As well as for bulk specimens, contact platforms were deposited using indium forming conducted areas with researched material [9].

Measurements of kinetic phenomena (specific conductivity $(\sigma)$ and the Hall factor $R$ ) of layers were performed in the temperature range $80-290^{\circ} \mathrm{K}$. As follows from results of measurements in Fig. 2, in layers, obtained by a)

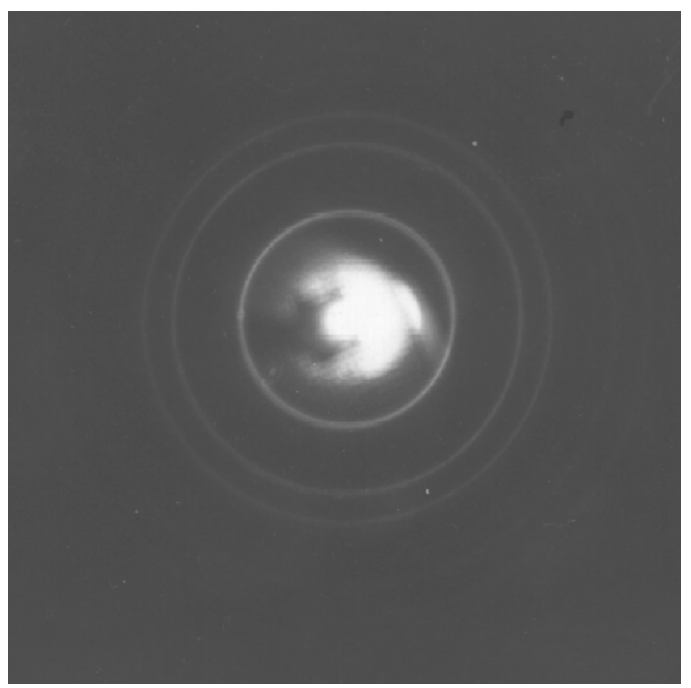

b)

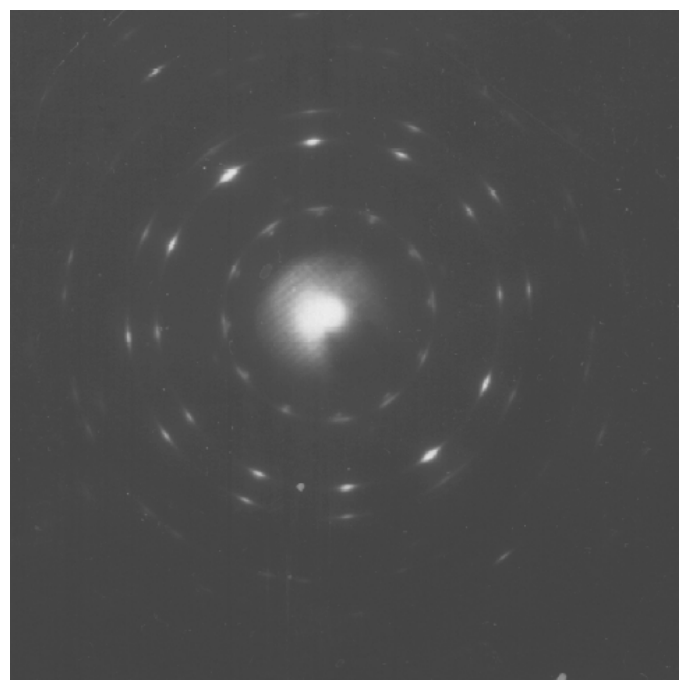

c)

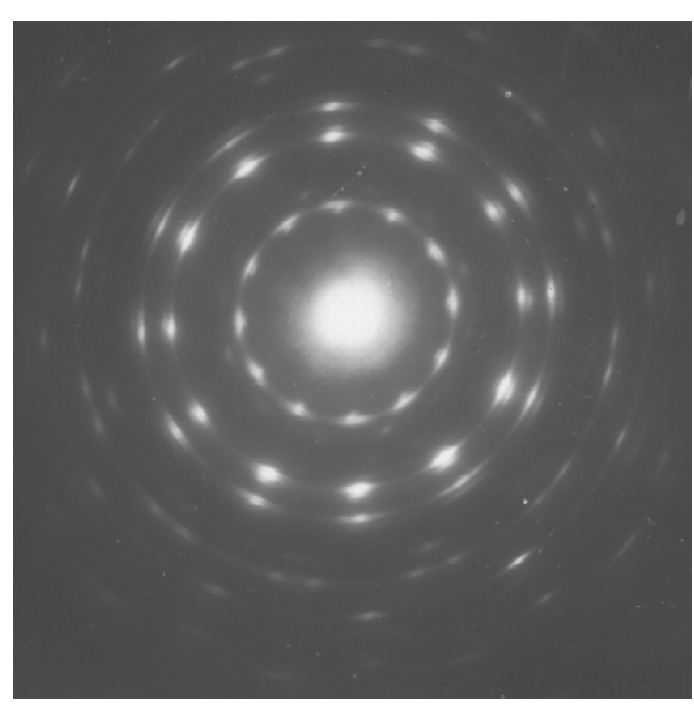

Fig. 1. Electron diffraction patterns of $\mathrm{Cd}_{0.25} \mathrm{Hg}_{0.75} \mathrm{Se}$ films obtained at different substrate temperatures: $\mathrm{a}-90^{\circ} \mathrm{C} ; \mathrm{b}-110^{\circ} \mathrm{C} ; \mathrm{c}-$ $120^{\circ} \mathrm{C}$ 


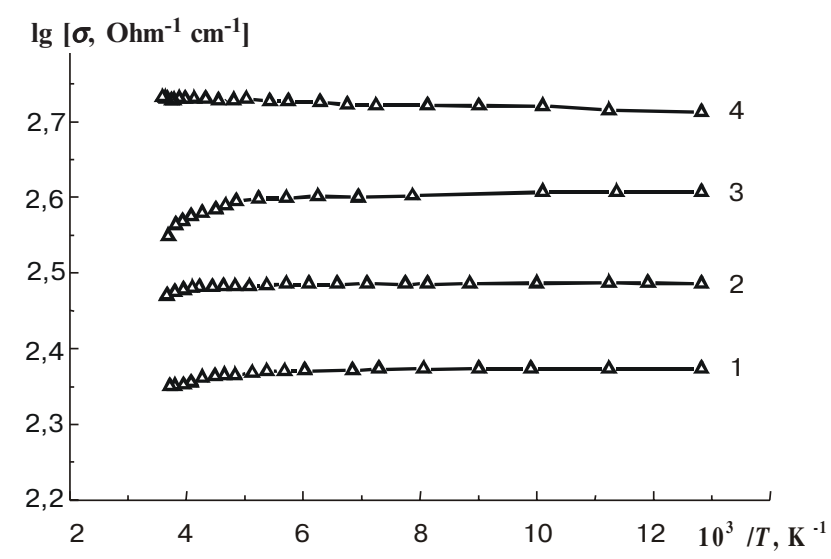

Fig. 2a. Temperature dependences of conductivity of $\mathrm{Cd}_{0.25} \mathrm{Hg}_{0.75} \mathrm{Se}$, films prepared by sputtering:

1,3,4-monocrystals; 2 -synthesized material, at substrate temperatures: $1-90^{\circ} \mathrm{C} ; 2,3,4-120^{\circ} \mathrm{C}$. In the case 4 monocrystals were sputtered in vacuum $\left(\sim 10^{-5}\right.$ Torr $)$.

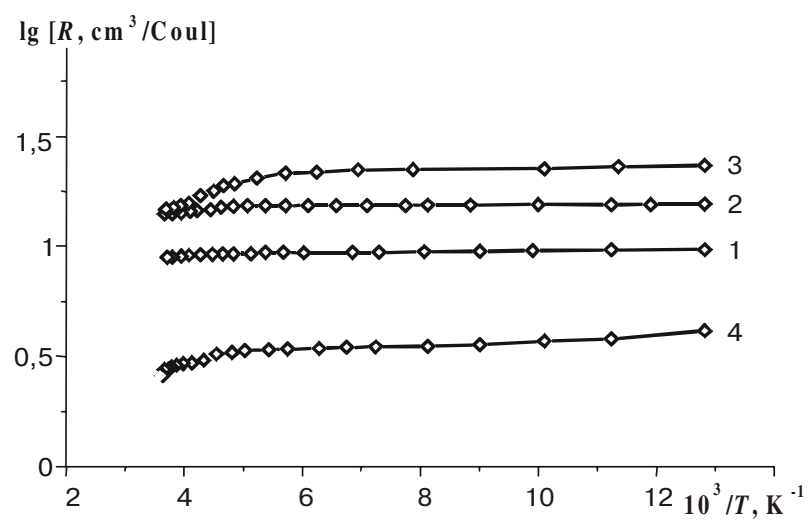

Fig. 2b. Temperature dependences of the Hall coefficient for films $\mathrm{Cd}_{0.25} \mathrm{Hg}_{0.75} \mathrm{Se}$ (the numbers of curves correspond to Fig. 2a).

evaporation of monocrystalline material, with growing substrate temperature during process of deposition specific conductivity grows. Similar behavior can be observed for the Hall too (curves 1, 3). It reaches maximum value for layers grown at substrate temperature $120^{\circ} \mathrm{C}$ and at further increasing of that temperature - is lowered. The growth of the Hall constant can be explained as follows. With increasing temperature of the substrate, the sizes of monocrystalline grains in layer are increased. The degree of growing crystal order is increased too. It results in decreasing concentration of current carriers. The re- duction of the Hall constant can be connected with repeated evaporating of mercury, that results in infringing stoichiometry of layers. Thus, the substrate temperature $120^{\circ} \mathrm{C}$ is optimum for growing layers $\mathrm{Cd}_{0.25} \mathrm{Hg}_{0.75} \mathrm{Se}$.

Mobility of current carriers (electrons) for layers grown in optimum conditions lies in the range $(5 \ldots 8)$. $\cdot 10^{2} \mathrm{~cm}^{2} I(\mathrm{~V} \cdot \mathrm{s})$, that is approximately 5 times below respective values for bulk monocrystalline samples [9].

Bearing in the mind that preparation of crystals $\mathrm{Cd}_{0.25} \mathrm{Hg}_{0.75} \mathrm{Se}$ is by labour-consuming process, we performed deposition of these layers from grown material. In Figs $2 \mathrm{a}$ and $2 \mathrm{~b}$ (the curve 2) submitted are $\sigma$ and $R$ dependences for layers prepared under optimum conditions. These layers differ little by their electrical properties from layers grown from monocrystalline material.

The curve 4 in Figs $2 a$ and $2 b$ represents dependence of electrical conductivity $\sigma$ and $R$ from temperature for layers $\mathrm{Cd}_{0.25} \mathrm{Hg}_{0.75} \mathrm{Se}$, grown in conditions of static vacuum $\left(10^{-5}\right.$ Torr $)$ without spraying getter at different temperatures of a substrate. Though given layers are grown at optimal temperature of a substrate, however, these have lower values of $\sigma$ and $R$, than those received in conditions of higher vacuum where active environment provides excluding residual gases.

From comparison of results obtained for layers and bulk samples [9] follows that the technique used by us permits to prepare layers of solid solutions $\mathrm{Cd}_{x} \mathrm{Hg}_{1-\mathrm{x}} \mathrm{Se}$ with properties close to that of bulk material.

\section{References}

1. Technology of thin layers. The directory. Eds: L. Misell, R. Gling, v.1. Sov. Radio, Moskva, 1977, 664 p. (in Russian)

2. M.X.Frankomb, G.E.Johnson, Preparation and properties of semiconductor layers. In: Physics of thin layers. v.5, Moskva, 1972, p. 140-240 (in Russian).

3. L.E. Misell, Preparation of thin films by cathode sputtering. In: Physics of thin layers. v.3, Mir, Moskva, 1968, p. 58-134 (in Russian).

4. A. Kurnosov, B. Joodin, The «know-how» of semiconductor devices. Visshaja shkola, Moskva, 1974, 400 p. (in Russian)

5. E. Koocherenko, The directory on the physical bases of vacuum engineering, Vishcha shkola, Kiev, 1981, 264 p. (in Russian).

6. N. Djulli. Laser technology and analysis of materials, Mir, Moskva, 1988, 504 p. (in Russian)

7. B. Gritsook, S. Nichiy, Preparation of layers by laser evaporation in conditions of static vacuum // PT № 2, p. 144-145 (1997).

8. Yu. Vorobjov, V. Dobrovolskiy, V. Striha, Methods of research of semiconductors, «Vishcha shkola», 1988, 232 p.(in Russian)

9. M. Gavaleshko, S. Paranchich, I.Babiy, About a structure of a conductivity band and mechanism of scattering in solid solutions $\mathrm{Cd}_{\mathrm{x}} \mathrm{Hg}_{1-\mathrm{x}} \mathrm{Se} / /$ Ukr. Fiz. Zhurnal.20(4), pp. 631-635 (1975). 